\title{
MODELO DE AVALIAÇÃO DE DESEMPENHO POR PERFORMANCE COMO PROMOTOR DE CICLOS DE MELHORIA NA PRÁTICA ANESTÉSICA
}

Leopoldo Muniz da Silva, Arthur de Campos Vieira Abib, Saullo Queiroz Silveira, Renata Mazzoni de Queiroz.

Introdução: A avaliação de desempenho por performance (ADP) objetiva ampliar o apoio ao desenvolvimento técnico-científico, aumentar as oportunidades de desenvolvimento pessoal e institucional e desenvolver ações educativas relacionadas à qualidade e segurança em saúde.

Objetivo: Analisar um modelo de avaliação de desempenho de médicos anestesiologistas como ferramenta para melhoria na assistência, educação médica continuada e segurança do paciente, comparando-se dois ciclos anuais.

Métodos: Um modelo de ADP para anesteiologistas foi construído incluindo os critérios: excelência operacional e qualidade no registro seguro (auditoria mensal de prontuários), participação em atividades de edução médica continuada e prática assistencial (adesão aos protocolos institucionais gerenciados). O desempenho foi avaliado em ciclos de anuais em 2017 e 2018. Os escores de desempenho foram subdivididos em curvas A (excelência), curvas B (adequado), curvas C (inadequados). Médicos classificados na curva C foram submetidos a teste de conformidade nas principais fragilidades apresentadas ao longo do ciclo anual.

Resultados: A ADP foi realizada para 92 anestesiologistas que prestam assistência em hospital de alta complexidade. Em 2017, 51,52\% dos médicos foram considerados como ADP inadequada. Médicos na curva A representaram 21,22\%. Em 2018, a ADP adequada foi observada em 59,29\% dos médicos avaliados, com melhora de $21 \%$ comparado ao ano interior $(p<0,05)$. Os principais fatores implicados na melhoria foram: melhora do registro seguro, melhora na transferência do cuidado para pacientes com indicação de UTI, curso de integração para novos médicos e formatação de um modelo padrão de boas práticas e registro para o prontuário eletrônico. No teste de conformidade para médicos na curva $\mathrm{C}$, a transferência de informação e o protocolo de controle glicêmico foram as principais fragilidades.

Quadro 1. Mapa de competências - Avaliação de desempenho médico
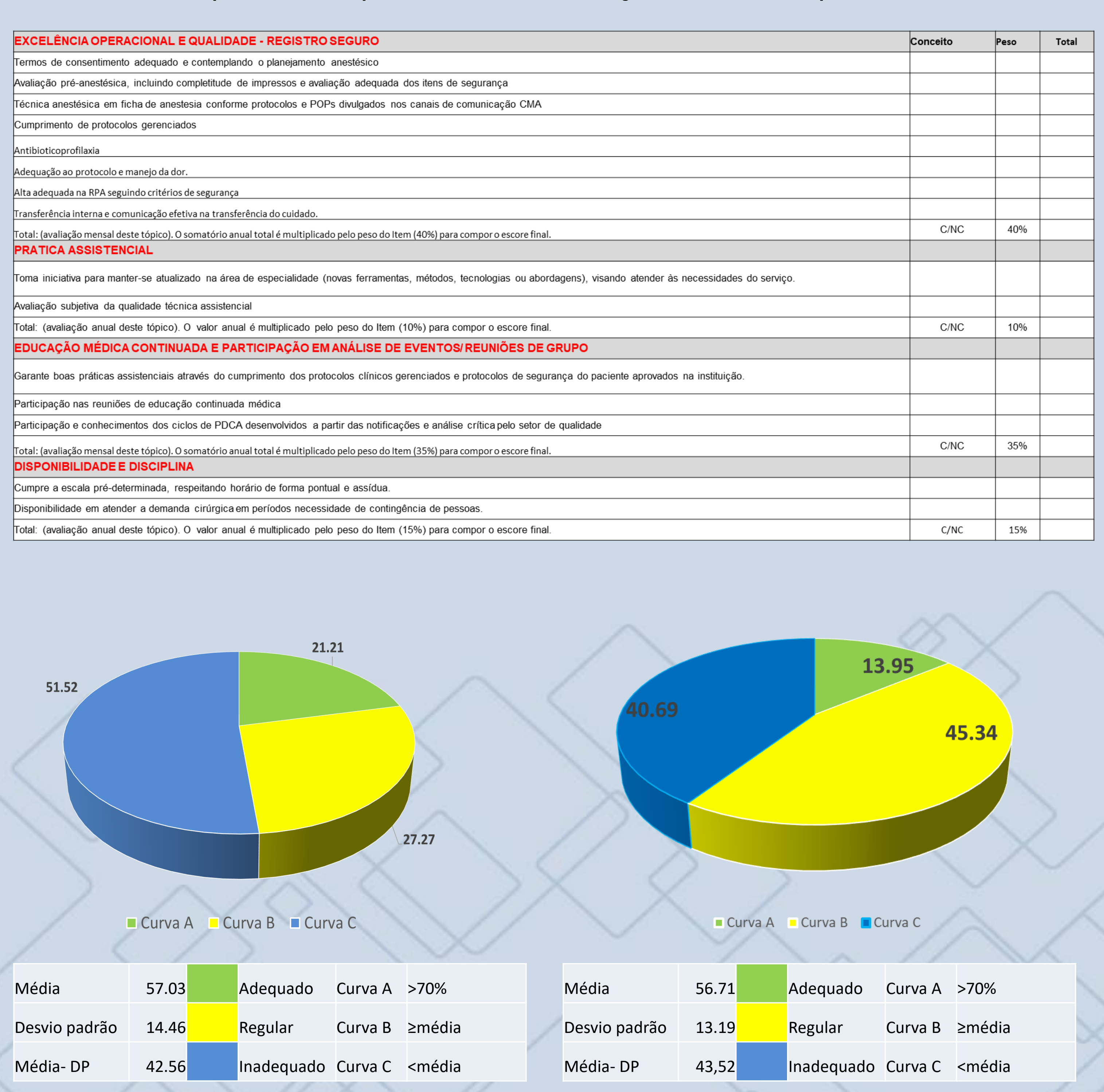

Figura 1. Resultado da avaliação de desempenho 2017/2018. estratificação por curvas

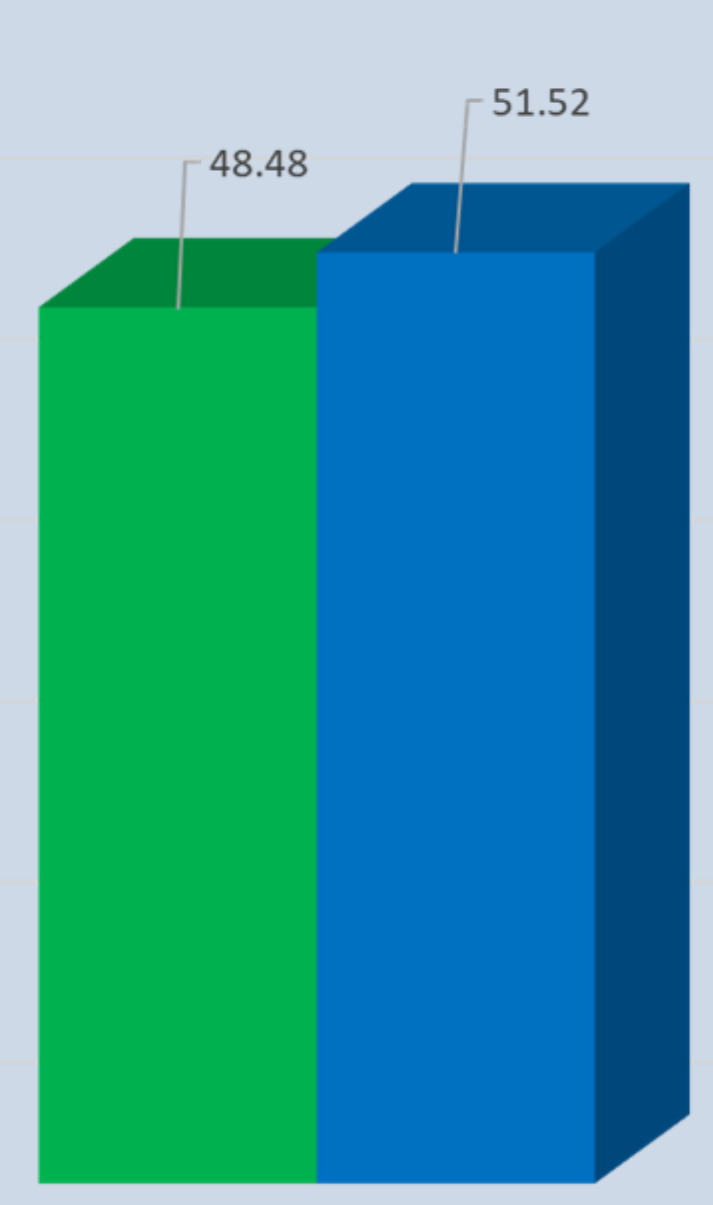

2017

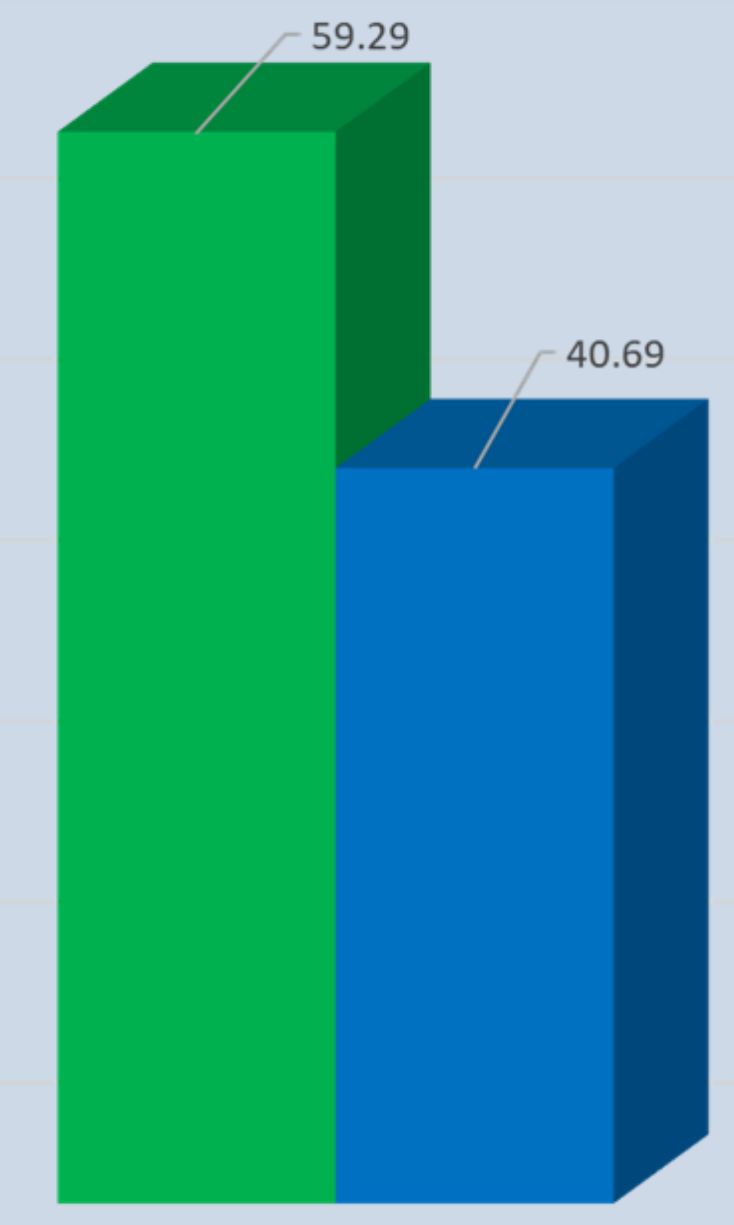

2018
Figura 2. Comparativo - Avaliação de desempenho 2017/2018. teste quiquadrado $p<0,05$.

Quadro 2. Resultado do teste de conformidade na Curva C - processo de reintegração para identificação de fragilidades.

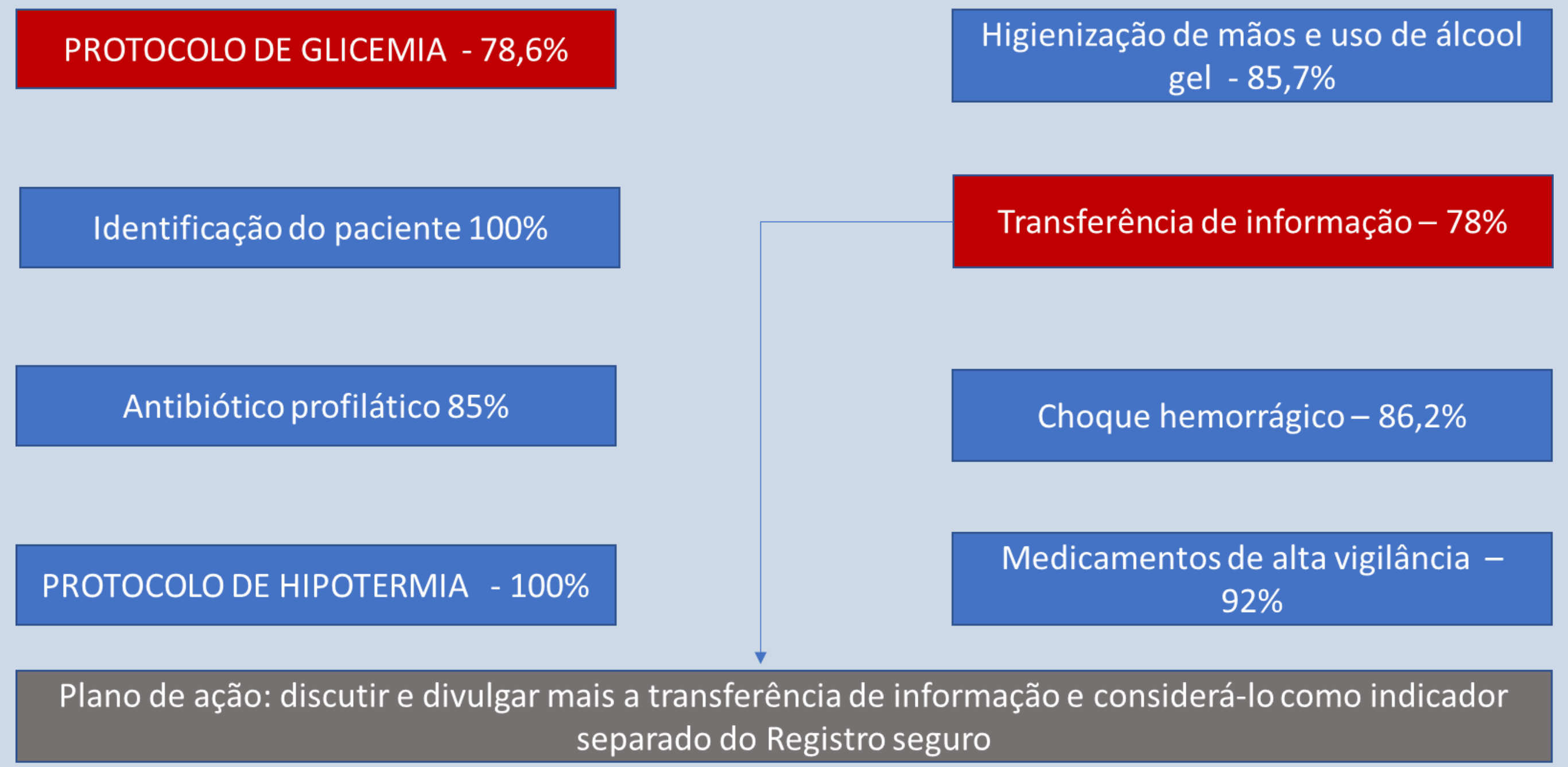

Conclusão: A ADP permite analisar fragilidades na prática assistencial e estabelecer melhorias baseadas no perfil de desempenho avaliado, garantindo uma maior efetividade de planos de ação.

Referência: Moacdieh N. Clutter in electronic medical records: examining its performance and attentional costs using eye tracking. Hum Factors. 2015 57(4):591-606. 